Nutr. Metabol. 1970;12:371-384

\title{
Varia
}

Tentative Rules for Generic Descriptors and Trivial Names for Vitamins and Related Compounds1

Recommended by the IUNS Committee on Nomenclature2

Introduction

1. The IUNS Committee on nomenclature recommends the adoption of the following 'tentative rules for vitamins and related compounds' by all adhering organizations to ensure uniformity in the nutrition literature. The need for 'tentative rules' was set forth by Prof. H. Dam and Dr. T.

Moore at the 7th International Congress of Nutrition in Hamburg in 1966 (Proceedings of the 7th International Congress of Nutrition, 1966, vol. V). Subsequently the Committee on

Nomenclature of the American Institute of Nutrition, under the chairmanship of Dr. S. R. Ames, drafted 'tentative rules' following customary usage in the United States. Their 'fourth draft' was approved by the Council of the American Institute of Nutrition and is consistent with the nomenclature now used by the Food and Nutrition Board, NASNRC, in their 7th edition, 1968, of 'recommended dietary Allowances'.

This draft was modified in correspondence between Prof. Dam and members of the IUNS Committee. When there has been no reason to the contrary the Committee's recommendations concur with those in the AIN draft or with those made at various times by joint IUPAC-IUB Commissions on Biochemical Nomenclature. Acknowledgements

1 Reprinted from Nutrition Abstracts and Reviews, vol. 40, pp. 395-400 (1970).

2 Comments on these Tentative rules, approved by the 8th International Congress of Nutrition, Prague, Czechoslovakia, in 1969, may be sent to any member of the IUNS Committee on Nomenclature: T. Moore (chairman), D. L. Duncan (secretary), S. R. Ames, W. Jaffé, C. Kawasaki, A. A. Pokrovsky, Y. Raoul, E. Sandi. 
Varia

are made to both these sources. In a revised form the AIN draft was used as a basis for discussions by those members of the IUNS Committee who attended the precongress meetings in Belgrade on August 20-23 1969 (S. R. Ames, USA, acting chairman; D. L. Duncan, UK, secretary; T. Moore, UK; A. A. Pokrovsky, USSR) and in Prague on 26 August 1969 (S. R. Ames; D. L. Duncan; T. Moore; W. Jaffé, Venezuela).

The existence of the vitamins was discovered by their biological action before their chemical nature was known. For that reason they were grouped under the generic term vitamins and identified by letters, sometimes with subscript numbers. In some cases the use of this system has persisted after the substances had been identified chemically, but in others the chemical nature was so soon elucidated that the 'vitamin' term was not used long enough to gain wide acceptance. The result is that a vitamin term and a chemical name are used synonymously, or that a vitamin term is used generically for a series of compounds with similar activity, or that the vitamin term has fallen out of use. In these 'tentative rules' it has been agreed that the vitamin term is of value particularly in its generic use to cover a class of essential organic nutrients, and it would be a retrograde step to discard it. The system of lettering to indicate a series of compounds with similar activity remains useful to nutritionists.

Trivial names and generic descriptors for the vitamins and related compounds are useful and necessary in nutrition literature. In each instance, the generic descriptor should be used to describe the family of compounds having vitamin activity and to modify such terms as 'activity', 'deficiency', etc. In defining families of compounds of like structure and similar biological activity, the 'tentative rules' retain the terms vitamins A, D, E, K, B-6, B-12 and C and redefine the terms niacin and folacin. The trivial names should be used only to identify the specific compound.

This committee feels that synonyms for a specific chemical compound are undesirable and lead to unnecessary complications in indexing and in computer retrieval. Therefore only one name is recommended for each vitamin or related compound.

4. The summation of the contributions to the dietary intake of different forms of the same vitamin is a practical necessity to nutri tionists. In most instances scanty information is available on the relative biological activities of different members of a family. Until 
Varia

373

additional data can be obtained IUNS can only suggest which substance seems to be the most suitable member of the family in terms of which nutritionists should aim to express their summation.

For vitamin A and its provitamins summation should be made in $\mathrm{mg}(\mu \mathrm{g})$ retinol equivalent. Provitamins, if their separate summation is required, should be expressed in $\mathrm{mg}(\mu \mathrm{g})$ B-carotene equivalent. It is emphasised that discretion must be used in the acceptance of values from food tables and in the interpretation of findings from biological tests. Thus, although retinol is to be used as the summation substance it is greatly inferior, in view of its instability, to all-transretinyl acetate (9-trans, 11-trans, 13-traíis-retinyl acetate) as the standard for biological tests. For vitamin E summations should be made in $\mathrm{mg}(\mu \mathrm{g})$ a-tocopherol equivalent. Although $\alpha$ tocopherol is to be used as the summation substance it is greatly inferior, in view of its instability and variable biological activity, to $\alpha$-tocopheryl acetate $\left(2 \mathrm{D}, 4^{\prime} \mathrm{D}, 8^{\prime} \mathrm{D}-\alpha\right.$-tocopheryl acetate from natural sources) as the standard for biological tests. Furthermore, selenium compounds or antioxidants which may show activity more or less similar to some functions of vitamin E should not be included in the term $\alpha$-tocopherol equivalent.

Other members of vitamin families suggested for purposes of summation, with similar reservations, are:

Vitamin D cholecalciferol equivalent

Vitamin K phytylmenaquinone (phylloquinone) equivalent

Vitamin B-12 cyanocobalamin equivalent

Folacinfolic acid equivalent

Niacin (tryptophan) nicotinamide equivalent.

Fat-soluble Vitamins and Related Compounds

1. Vitamin A and Provitamin A Carotenoíds

1. The term vitamin A should be used as the generic descriptor for all /S-ionone derivatives, other than provitamin A carotenoids, exhibiting qualitatively the biological activity of retinol. Thus, phrases such as 'vitamin A activity', 'vitamin A deficiency' and 'vitamin A in the form of...' represent preferred usage. 
The compound with formula $\mathrm{I}(\mathrm{R}=-\mathrm{CH} 2 \mathrm{OH})$, also known as vitamin $\mathrm{A}$, vitamin A alcohol, vitamin Ax, vitamin Aj alcohol, axerophthol or axerol, should be designated retínol.

Esters of retinol should be designated retínyl esters.

The compound with formula I $(\mathrm{R}=-\mathrm{CHO})$, also known as vitamin $\mathrm{A}(\mathrm{Aj})$ aldehyde, retinene or retinal, should be designated retínaldehyde.

The compound with formula $\mathrm{I}(\mathrm{R}=-\mathrm{COOH})$, having partial vitamin A activity and also known as vitamin A acid, should be designated retínoíc acid.<smiles>[R]C=C(C)C=CC=C(C)C=CC1=C(C)C=CCC1(C)C</smiles>

II

The compound 3-dehydroretinol, with formula II $(\mathrm{R}=-\mathrm{CH} 2 \mathrm{OH})$, also known as vitamin $\mathrm{A} 2$, should be designated dehydro-retínol.

The compound 3-dehydroretinaldehyde, with formula II $(\mathrm{R}=-\mathrm{CHO})$, also known as retinene2,3-dehydroretinal or dehydro-retinal, should be designated dehydroretinaldehyde.

The compound 3-dehydroretinoic acid, with formula II $(\mathrm{R}=-\mathrm{COOH})$, should be designated dehydroretínoíc acid.

The term provitamin A carotenoíd should be used as the generic descriptor for all carotenoids exhibiting qualitatively the biological activity of/S-carotene. When referring to the biological activity of the provitamin A carotenoids, the phrase 'provitamin A activity' represents preferred usage. 
Varia

375

Trivial names for specific carotenoids are under consideration.

The term retínol equivalent may be used as described in section 4 of the Introduction.

2. Vitamin D

1. The term vitamin D should be used as the generic descriptor for all steroids exhibiting qualitatively the biological activity of chole-calciferol. Thus, phrases such as 'vitamin D activity' and 'vitamin D deficiency' represent preferred usage.

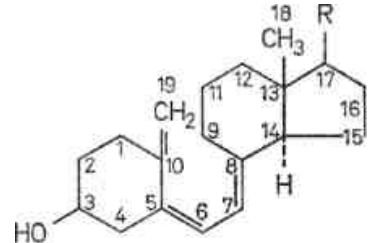

111

2. The compound with formula III

$\mathrm{Me}(\mathrm{R}=-\mathrm{C}-\mathrm{CH} 2-\mathrm{CHo}-\mathrm{CH},-\mathrm{C}-\mathrm{Me} 2)$,

I “I

$\mathrm{H} \quad \mathrm{H}$

also known as vitamin D3, should be designated cholecalcíferol.

3. The compound with formula III

$\mathrm{Me} \quad \mathrm{Me}$

$(\mathrm{R}=-\mathrm{C}-\mathrm{C}=\mathrm{C}-\mathrm{C}-\mathrm{C}-\mathrm{Me} 2), \mathrm{H}$ H H H H also known as vitamin $\mathrm{D} 2$ or calciferol, should be designated ergo-calciferol.

4. The compound with formula III Me

$(\mathrm{R}=-\mathrm{C}-\mathrm{CH} 2-\mathrm{CH} 2-\mathrm{CH} 2-\mathrm{C}-\mathrm{Me} 2)$

I I

$\mathrm{H} \quad \mathrm{OH}$

should be designated 25-hydroxycholecalciferol. 
5. Esters of cholecalciferol and ergocalciferol should be designated cholecalcíferyl esters and ergocalcíferyl esters, respectively.

3. Vitamin E

The term vitamin E should be used as the generic descriptor for all tocol and tocotrienol derivatives exhibiting qualitatively the biological activity of $\alpha$-tocopherol. Thus, phrases such as 'vitamin E activity', 'vitamin E deficiency' and 'vitamin $\mathrm{E}$ in the form of...' represent preferred usage.

The term tocopherols should be used as the generic descriptor for all methyl tocols. Thus the term 'tocopherol' is not synonymous with the term 'vitamin E'.

The compound isolated from natural sources, $2 \mathrm{D}, 4^{\prime} \mathrm{D}, 8^{\prime} \mathrm{D}-\alpha$-toco-pherol or $2 \mathrm{R}, 4^{\prime} \mathrm{R}, 8^{\prime} \mathrm{R}-\alpha$ tocopherol with the formula IV $(\mathrm{Rx}=\mathrm{R} 2=\mathrm{R} 3=-\mathrm{Me})$, also known as á"- $\alpha$-tocopherol, should be designated $\alpha$-tocopherol.

The mixture of the eight possible stereoisomers of $\alpha$-tocopherol commonly synthesized from racemic isophytol and also known as 2DL,4'DL, $8^{\prime} \mathrm{DL}-\alpha$-tocopherol, $2 \mathrm{RS}, 4^{\prime} \mathrm{RS}, 8^{\prime} \mathrm{RS}-\alpha$ tocopherol or $\mathrm{d} /-\alpha$-toco-pherol should be designated all-rac.-a-tocopherol.

The mixture of two isomers of $\alpha$-tocopherol synthesized from natural phytol and also known as 2DL,4'D, 8'D- $\alpha$-tocopherol, 2RS, 4'R, 8'R- $\alpha$-tocopherol or 2- $\mathrm{d} /$ - $\alpha$-tocopherol should be designated $2 \mathrm{dl}-\mathrm{a} \cdot$ tocopherol. The acetate ester of this mixture of two isomers was the former International Standard for vitamin E (J.Nutr. 90:109 [1966]).

The compound $2 \mathrm{~L}, 4^{\prime} \mathrm{D}, 8^{\prime} \mathrm{D}-\alpha$-tocopherol or $2 \mathrm{~S}, 4^{\prime} \mathrm{R}, 8^{\prime} \mathrm{R}$ - $\alpha$-toco-pherol, also known as the epimer of d-a- tocopherol, 2/- $\alpha$-tocopherol or /- $\alpha$-tocopherol, should be designated $2 \mathrm{~L}$ - $\alpha$-tocopherol.

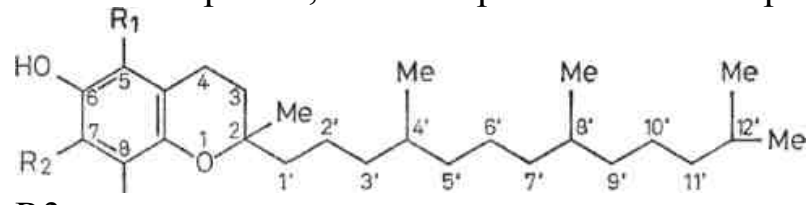

R3

IV

7. The compound 5,8-dimethyltocol with formula IV $(\mathrm{Rx}=\mathrm{R} 3=-\mathrm{Me} ; \mathrm{R} 2=-\mathrm{H})$, isolated from natural sources, should be designated $\beta \cdot$ tocopherol. 
Varia

377

The compound 7,8-dimethyltocol with formula IV $(\mathrm{Rj}=-\mathrm{H} ; \mathrm{R} 2=\mathrm{R} 3=-\mathrm{Me})$, isolated from natural sources, should be designated $\gamma$-tocopherol.

The compound 8-methyltocol with formula IV $(\mathrm{Rj}=\mathrm{R} 2=-\mathrm{H}$; R3 $=-\mathrm{Me})$, isolated from natural sources, should be designated ô-tocopherol.

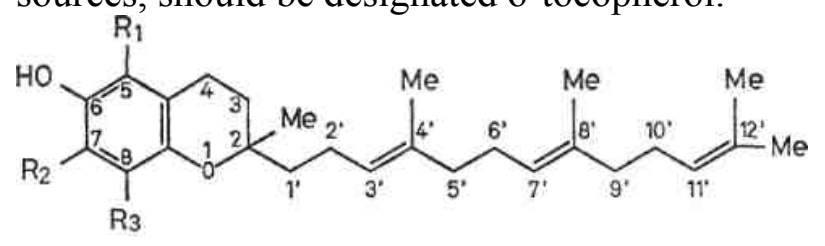

$\mathrm{V}$

The compound 5,7,8-trimethyltocotrienol with formula $\mathrm{V}(\mathrm{Rx}=\mathrm{R} 2=\mathrm{R} 3=-\mathrm{Me})$, isolated from natural sources and also known as $\zeta 1$ or $\mathrm{C} 2 \cdot \mathrm{t}^{\mathrm{0}}$ copherol or tocochromanol-3, should be designated a-tocotríenol.

The compound 5,8-dimethyltocotrienol with formula $\mathrm{V}(\mathrm{Rx}=\mathrm{R} 3=-\mathrm{Me} ; \mathrm{R} 2=-\mathrm{H})$, isolated from natural sources and also known as $\varepsilon$-tocopherol, should be designated $\beta$-tocotríenol. The compound 7,8-dimethyltocotrienol with formula V $\left(\mathrm{R}-\mathrm{i}^{\wedge}=-\mathrm{H} ; \mathrm{R} 2=\mathrm{R} 3=-\mathrm{Me}\right)$, isolated from natural sources and also known as ${ }^{\wedge}$-tocopherol or plastochromanol-3, should be designated $\gamma$-toco-trienol.

The compound 8-methyltocotrienol with formula $\mathrm{V}(\mathrm{R} 1=\mathrm{R} 2=-\mathrm{H} ; \mathrm{Rs}=-\mathrm{Me})$, isolated from natural sources, should be designated $\delta$-tocotríenol.

Esters of tocopherols and tocotrienols should be designated tocopheryl esters and tocotríenyl esters, respectively.

The term a-tocopherol equivalent may be used as described in section 4 of the Introduction.

4. Vitamin K

1. The term vitamin $\mathrm{K}$ should be used as the generic descriptor for 2-methyl-1,4-naphthoquinone and all derivatives exhibiting qualitatively the biological activity of phytylmenaquinone (phylloquinone). Thus, phrases such as 'vitamin K activity' and 'vitamin K deficiency' represent preferred usage. 
Varia

2. The compound 2-methyl-1,4-naphthoquinone with formula VI, having partial vitamin $\mathrm{K}$ activity and also known as menadione, should be designated menaquínone.

$\mathrm{C} \phi \mathrm{r}$.

\section{o VI}

3. The compound 2-methyl-3-phytyl-1,4-naphthoquinone with formula VII, also known as vitamin Kx or phylloquinone, should preferably be designated phytylmenaquinone.

0<smiles>Cc1cccc2ccccc12</smiles>

$-\mathrm{CH} 2-\mathrm{CH}=\mathrm{C}-\mathrm{CH} 2-[\mathrm{CH} 2-\mathrm{CH} 2-\mathrm{CH}-\mathrm{CH} 2] 3-\mathrm{H}$

$\mathrm{Me} \quad \mathrm{CH} 3 \quad \mathrm{CH} 3$

0

VII

The compounds known as vitamin $\mathrm{K} 2$ should be designated multiprenylmenaquinones. Thus, a vitamin K2 having a side chain consisting of 6 prenyl units and also known as menaquinone- 6 should preferably be designated prenylmenaquínone- 6 ; a vitamin $\mathrm{K} 2$ having a side chain consisting of 7 prenyl units and also known as mena-quinone- 7 should preferably be designated prenylmenaquinone-7.

In general the use of abbreviations for the compounds dealt with in chapter 4., 3-4 above is not recommended. Should abbreviation be necessary the following forms are permissible: phytylmenaquinone, PMQ; prenylmenaquinone-6, MQ-6; prenylmenaquinone-7, MQ-7. The IUPAC-IUB tentative rules for nomenclature of quinones with isoprenoid side chains ( $\mathrm{J}$. biol. Chem. 241: 2989-2991 [1966]) may be used with the reservations following from chapter 4., 2-5 above. 


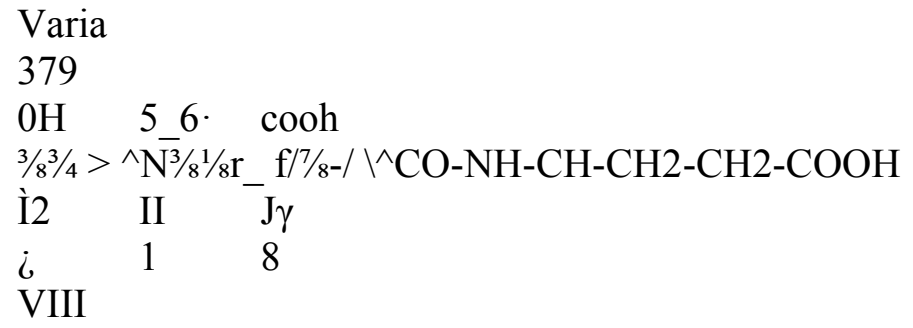

Water-soluble Vitamins and Related Compounds

\section{Folacín}

The term folacín should be used as the generic descriptor for folic acid and related compounds exhibiting qualitatively the biological activity of folic acid. Thus, phrases such as 'folacin activity' and 'folacin deficiency' represent preferred usage.

The compound monopteroylglutamic acid with formula VIII should be designated folic acid. Folic acid derivatives in which the glutamic acid residue is combined through a peptide bond with another glutamic acid residue which may or may not be similarly combined with a third glutamic acid residue and so on should be designated folic acid glutamates $(\mathrm{N})$, where $\mathrm{N}$ indicates the number of glutamic acid residues.

The compound tetrahydropteroylglutamic acid, also known as PGAH4, THFA or tetrahydrofolacin, should be designated tetrahydrofolic acid.

The compound N5-formyltetrahydropteroylglutamic acid, also known as N5-F-PGAH4, citrovorum factor, 'CF', leucovorin, folinic acid or N5-formyl THFA, should be designated 5formyltetrahydrofolic acid.

The compound N10-formyltetrahydropteroylglutamic acid, also known as N10-F-PGAH4, heatlabile citrovorum factor, 'HLCF' or N10-formyl THFA, should be designated 10formyltetrahydrofolic acid.

The compound N5-methyltetrahydropteroylglutamic acid, also known as N5-M-PGAH4, 'prefolic A', N5-methyltetrahydrofolacin or N5-methyl THFA, should be designated 5methyltetrahydrofolic acid.

In general the use of abbreviations for the compounds dealt with in chapter 5., 4-7 above is not recommended. Should abbreviation be necessary the following forms are permissible:

tetrahydrofolic 
9. Related compounds with folacin activity should be named and abbreviated in accordance with the IUPAC-IUB tentative rules for nomenclature and symbols for folic acid and related compounds (J. biol. Chem. 241: 2991-2992 [1966]).

6. Níacín

The term níacín should be used as the generic descriptor for pyridine 3-carboxylic acid and derivatives exhibiting qualitatively the biological activity of nicotinamide. Thus, phrases such as 'niacin activity' and 'niacin deficiency' represent preferred usage.

The compound pyridine 3-carboxylic acid with formula IX $(\mathrm{R}=-\mathrm{COOH})$, also known as niacin or vitamin PP, should be designated nicotinic acid.<smiles>[R]c1cccnc1</smiles><smiles>Cc1cc2nc3c(=O)nc(O)nc-3n(CCO)c2cc1C</smiles>

$\mathrm{X}$

The compound with formula IX $(\mathrm{R}=-\mathrm{CONH} 2)$, also known as niacinamide or nicotinic acid amide, should be designated nícotínamíde.

The term nícotínamíde equivalent may be used as described in section 4 of the Introduction. 
Varia

381

7. Riboflavín

1. The compound with formula X, also known as vitamin B2, lactoflavin(e) or riboflavine, should be designated riboflavin. Its use in phrases such as 'riboflavin activity' and 'riboflavin deficiency' represents acceptable usage.<smiles>Cc1ncc(CN2CCN(CCO)C2)c(C)n1</smiles>

XI

8. Thíamín

1. The cation with formula XI, also known as vitamin B13/8 aneurin(e) or thiamine, should be designated thiamín. Its use in phrases such as 'thiamin activity' and 'thiamin deficiency' represents acceptable usage.

9. Vitamin B-6

The term vitamin B-6 should be used as the generic descriptor for all 2-methylpyridine derivatives exhibiting qualitatively the biological activity of pyridoxine. Thus, phrases such as 'vitamin B-6 activity' and 'vitamin B-6 deficiency' represent preferred usage.

The compound 3-hydroxy-4,5-bis(hydroxymethyl)-2-methyl-pyridine with formula XII ( $\mathrm{R}=-$ $\mathrm{CH} 2 \mathrm{OH}$ ), also known as vitamin B6, adermin or pyridoxol, should be designated pyridoxine.<smiles>[Y19]c1ncc(CO)c(O)c1[R]#N</smiles>

XII

The compound with formula XII $(\mathrm{R}=-\mathrm{CHO})$, also known as pyridoxaldehyde, should be designated pyrídoxal.

The compound 3-hydroxy-4-methylamino-5-hydroxymethyl-2-methylpyridine with formula XII $(\mathrm{R}=-\mathrm{CH} 2 \mathrm{NH} 2)$ should be designated pyrídoxamíne. 
The term vitamin B-12 should be used as the generic descriptor for all corrinoids exhibiting qualitatively the biological activity of cyanocobalamin. Thus, phrases such as 'vitamin B-12 activity' and 'vitamin B-12 deficiency' represent preferred usage.

The term corrinoids should be used as the generic descriptor for all compounds containing the corrin nucleus and thus chemically related to cyanocobalamin. The term 'corrinoid' is not synonymous with the term 'vitamin B-12'.

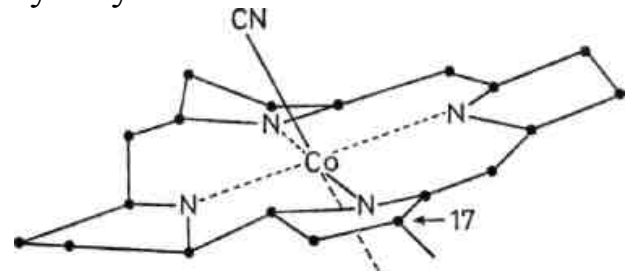

$\mathrm{CH} 2$

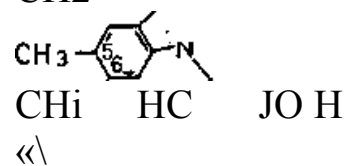

\section{LH3 HOJ 1 1/8VCH2}

$-\mathrm{c}^{1 / 8} \mathrm{I}$

$\backslash \mathrm{OH}$

${ }^{\circ} \mathrm{H} 0 \mathrm{H}$ CH3 P 00 XIII

The compound $\alpha$-(5,6-dimethylbenzimidazolyl) cobamide cyanide with formula XIII, also known as vitamin B12 or cyanocobal-amine, should be designated cyanocobalamin.

The compound $\alpha$-(5,6-dimethylbenzimidazolyl) hydroxocob-amide, also known as vitamin B12a, vitamin B12jj, aquocobalamin or hydroxocobalamine, should be designated hydroxocobalamín. The compound $\alpha$-(5,6-dimethylbenzimidazolyl) cobamide nitrite, also known as vitamin B12c or nitritocobalamine, should be designated nítritocobalamín.

Related compounds with vitamin B-12 activity should be named in accordance with the IUPACIUB tentative rules for nomenclature of corrinoids (J. biol. Chem. 241: 2992-2994 [1966]). 
Varia

383

11. Vitamin C

1. The term vitamin $C$ should be used as the generic descriptor for all compounds exhibiting qualitatively the biological activity of ascorbic acid. Thus, phrases such as 'vitamin C activity' and 'vitamin $\mathrm{C}$ deficiency' represent preferred usage.

XIV

The compound with formula XIV, also known as vitamin C or L-ascorbic acid, should be designated ascorbic acid.

The compound also known as L-dehydroascorbic acid should be designated dehydroascorbíc acid.

$\mathrm{H} 3 \mathrm{C} \mathrm{OH}$

I I

$\mathrm{HOCH} 2-\mathrm{C}-\mathrm{CH}-\mathrm{CO}$

$\mathrm{H} 3 \mathrm{C} \quad \mathrm{HN}-\mathrm{CH} 2-\mathrm{CH} 2-\mathrm{COOH}$

$\mathrm{XV}$

12. Pantothenic Acid

1. The compound with formula XV, also known as pantoyl-/?-alanine, should be designated pantothenic acid. Its use in phrases such as 'pantothenic acid activity' and 'pantothenic acid deficiency' represents acceptable usage.

0

II

$\mathrm{Hl} \cdot \mathrm{T}^{\wedge} \mathrm{NH}$

I I

$\mathrm{HC} \quad \mathrm{CH}$

I I

H2C. .CH. $\left(\mathrm{C}^{1 / 8} / 8\right) 4 . \mathrm{COOH}$

XVI 
Varia

13. Bíotín

1. The compound with formula XVI, also known as coenzyme R, should be designated biotin. Its use in phrases such as 'biotin activity' and 'biotin deficiency' represents acceptable usage.

14. Cholíne

1. The compound with formula $\left(\mathrm{CI}^{3} / 4 \mathrm{gNCHaCHaOH}\right.$ should be designated cholíne. Its use in phrases such as 'choline activity' and 'choline deficiency' represents acceptable usage.

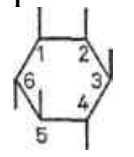

XVII

15. Myo-ínosítol

1. The compound with formula XVII, also known as inositol or mesoinositol, should be designated myo-ínosítol. Its use in phrases such as 'myo-inositol activity' and 'myo-inositol deficiency' represents acceptable usage (Europ. J. Biochem. 5: 1-12 [1968]).

$\mathrm{NH} 2$

$\Phi$

COOH XVIII

16. p-Amínobenzoíc Acid

1. The compound with formula XVIII should be designated p-amínobenzoíc acid. Its use in phrases such as 'p-aminobenzoic acid activity' and 'p-aminobenzoic acid deficiency' represents acceptable usage. 